\section{Research Article}

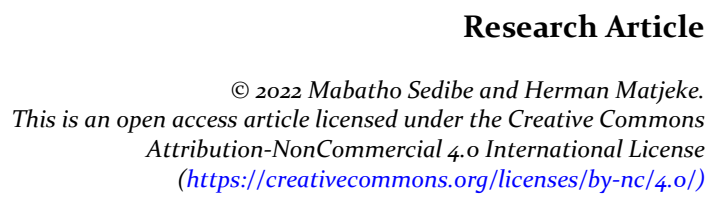

(https://creativecommons.org/licenses/by-nc/4.o/)

\title{
Exploring Primary School Principals' Experiences in Supporting Teachers Living with HIV/AIDS in Gauteng Province
}

\author{
Mabatho Sedibe \\ Herman Matjeke \\ Department of Educational Psychology, \\ University of Johannesburg, \\ P.O. Box 524, Auckland-Park, \\ Johannesburg 2006, \\ South Africa
}

DOI: https://doi.org/10.36941/mjss-2022-00o5

\begin{abstract}
The study highlighted the exploration and description of the primary school principals' experiences in supporting teachers living with HIV/AIDS in Gauteng Province, South Africa. As a result of qualitative research method through literature review and interviews which were used in collecting data from the primary school participants, the results revealed that at primary level, school principals still lack the experiences in as far as supporting their teachers living with HIV/AIDS in Gauteng province is concerned.
\end{abstract}

Keywords: exploration, primary school, experiences, HIV/AIDS, South Africa

\section{Introduction and the Background of the Study}

Although Human Immunodeficiency Virus (HIV), can be controlled to a certain degree, and be reduced to a chronic disease if well treated, it should still be perceived as an epidemic which may be fatal as it causes Acquired Immune Deficiency Syndrome (AIDS) which could result in many diseases that finally lead to death in human beings.

From the above statement there is still no cure to combat HIV/AIDS epidemic, almost thirty years later after the surfacing of the disease. As a result, HIV/AIDS has become a health, education, economic, social and development challenge in South Africa and the entire world. "About 6, 4 million people were estimated to be living with HIV/AIDS in 2012 in South Africa (Shisana,2013). Shisana (2013), further states that the prevalence of HIV/AIDS increased from $10.6 \%$ in 2008 to 12, 3\% in 2012 as reflected in the Human Science Research Council (HSRC) Household survey released in 2012". The survey has also revealed that "2 million people in 2012 were on Antiretroviral (ARV) treatment in South Africa". This treatment has paid off because it attempts to save people's lives and stabilises the impact on education. South Africa has unfortunately stayed behind in implementing the HIV/AIDS intervention strategies and programmes (e.g., distributing the ARV) because of denialism and a lack of political will by the administration of the South African government. The denialism has not only affected the South African social fibre but has generally also affected the education system.

Teachers living with HIV/AIDS are those teachers who have at least one or more opportunistic 
infection (e.g., TB, weight loss, skin cancer or diarrhoea). Education about HIV/AIDS prevention and provision of general knowledge about the disease could have been instituted at schools, starting with the children, teachers as well as with the school principals. There is a greater likelihood of these teachers living with HIV/AIDS to need support. The principals should aim at guiding and coordinating activities for the learners, teachers, and other members of the school human resources on how to manage the challenges of the HIV/AIDS disease at school. The initiative is important to preserve lives and educate while research for the cure is taking place globally. Experienced principals with life-skills knowledge are best positioned to play a significant role to manage teachers living with HIV/AIDS effectively.

Various initiatives and strategies at school level were formulated (such as awareness campaigns, workshops, and distribution of HIV/AIDS information pamphlets) to curb the impact of HIV/AIDS as it was killing many teachers (Bennel, 2005). According to ${ }^{2}$, "the education system was extremely affected especially in four main areas that is, in government, community, school and the household that collectively determined how the epidemic affected the supply and demand for education." "The process of teaching and learning was adversely affected as a result of the number of teachers who died of AIDS related illness in South Africa." Mbelle \& Setswe (2008). It is also known that the HIV/AIDS disease also affected teacher productivity e.g., high level of absenteeism emerged and high morbidity among teachers was realised, which finally resulted in a reduction in the number of teacher hours available. During the dawn of the twenty first century and long before the ARV era, HIV/AIDS was hard on the quality of life of many teachers and learners, therefore the quality of education was compromised. This statement is supported by Wood \& Webb (2008) when mentioning that "HIV/AIDS is impacting severely on the education system".

\section{Theoretical Framework}

This research focuses on the primary school principals' experiences in supporting teachers living with HIV/AIDS and making these teachers function effectively in the teaching and learning process despite their HIV/AIDS status. The theoretical framework underpinning this study is Brofenbrenner's eco-systemic theory. Kindly see the diagram below:

Bronfenbrenner (1986) classified a person's environment into the microsystem, mesosystem, Exosystem, macrosystem, and chronosystem. The Ecological Model is described as a series of concentric circles as indicated in Figure 2.1, which put an individual at the centre and is surrounded by a larger social system that is unified.

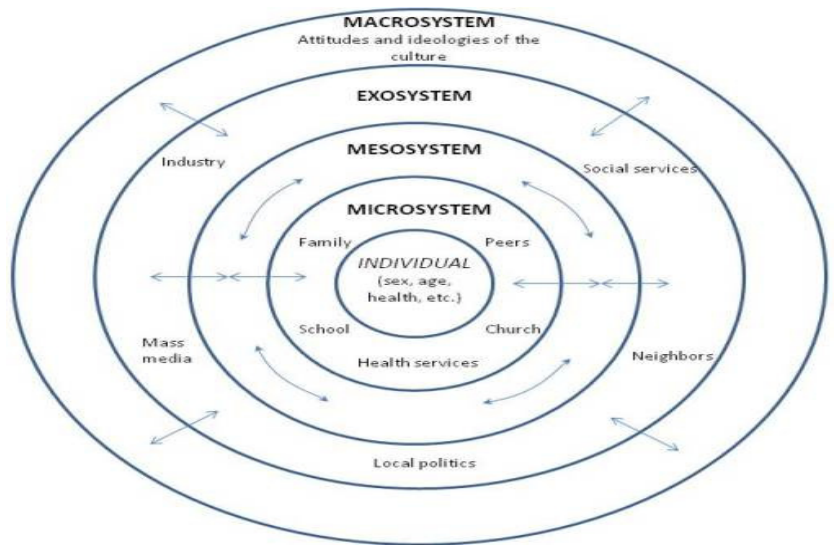

Figure 2.1: The Ecological Model indicating the social context of human development

Source: Adapted from Bronfenbrenner (1979:24) 
According to this theory's perspective, the school is seen as an ecosystem that evolves from a blend of ecological and systems which shows that teachers, families and the school communities are linked in dynamic interdependent and interacting relationship. For example, when one teacher is affected or infected with HIV/AIDS, the entire school, the education system, and the community become automatically affected. The ecology and the education systems according to ${ }^{6}$ "are compared to the spider grid which is likened to a system". What happens in any part of the network affects what happens in other parts of the system for example when an insect is trapped in the grid, the spider is alerted, and it can sense that there is an insect trapped in the grid. The insect is consumed by the spider as food and the system is sustained. When the web is broken then the spider starts the repairing process in preparation of trapping a fly again. The demise of the insect affects other systems, thus, the teachers and the principals at schools go through the same process when one of their own is infected or affected by HIV/AIDS. The principals would have to develop and apply their experiences in supporting primary school teachers living with HIV/AIDS in schools by formulating plans, strategies to implement and interpret activities that will facilitate the support of teachers living with HIV/AIDS and to deal with the threats of HIV/AIDS at school.

The primary schools are an important basis of any education system, which plays an important foundational system to expose and unlock the learning process of learners in the educational system. Learners who attend primary schools are in their formative life stages and as a result they need to receive firm educational foundation. This research views the primary education level as the important basis that need to prepare learners for high school and later life. The education in primary schools should therefore be well structured and teachers need to be knowledgeable and should honour their obligation. They should be present and on time at schools daily. They need to be stress free, not traumatised, and not intimidated, receive medical treatment when sick and their colleagues need to be sympathetic and should be supported by the school community and the School Management Team (SMT). A healthy primary school will be able to provide a healthy education and will have learners who leave with a reinforced foundation for high school and tertiary institution. Hence it is important for school principals to support all teachers irrespective of their HIV/AIDS status so that they can always be effective and efficient in their roles as teachers.

\section{Phutang District (Pseudo-nym) and HIV/AIDS}

Phutang is an area of mixed economy with its municipality being the largest based on the economic concentration with industrial activities. Unemployment is excessive, opening for HIV/AIDS momentum as many industrial establishments closed because of the poor economic condition in the region. The poverty rate is $45 \%$ and it is explicit among the various communities living in the area. The Local Research Group indicated in 2005 that "the lack of employment opportunities has escalated from $37 \%$ in the nineties to $48 \%$ in the late twenties (Sedibeng District Municipality, Annual Report, 2011). "The population of Phutang (pseudo-nym) is growing as people from the surrounding farms are migrating into the area seeking survival and housing opportunities. Phutang is a well-located district and has the potential of attracting investors to the area, however this positive interest is quickly diminishing because of the HIV prevalence rate in the area. The socio-economic impact of HIV/AIDS has devastating consequences to the population growth and human resources development. "Phutang has an HIV/AIDS prevalence of $35 \%$ ". The report is comparable to the routine Voluntary Care and Testing (VCT) statistics consolidated on annual basis (Sedibeng District Municipality, Annual Report, 2011).

\section{Research Question}

Research question is that which provides direction the researcher must follow in the development of the study. The research question is important in any research study because it assists the researcher 
in coming up with ideas of answering the question. Based on the above discussion, the research question in this study is formulated as: What are the primary school principals' experiences in supporting teachers living with HIV/AIDS among Teachers in Gauteng Province.

\section{Aim of the study}

Based on the preceding discussion, the aim of this study is to explore, describe, and interpret the primary school principals' experiences in supporting teachers living with HIV/AIDS among teachers in Gauteng Province.

In this way the research will inform educational practices on how to support teachers living with HIV/AIDS. Such teachers ought to be supported by the school principals and the School Management Teams (SMTs) within the schools.

The researchers identified that there is limited research conducted on the primary school principals' experiences in supporting teachers living with HIV/AIDS hence this study on the primary school principals' experiences in supporting teachers living with HIV/AIDS in Gauteng province. For example, Louw, Shisana, Peltzer, \& Zungu (2009). conducted a study on "examining the impact of HIV/AIDS on South African teachers". Other researchers focussed on the effect of HIV/AIDS on teaching and learning in the classroom and on the leadership role of principals in managing HIV/AIDS at schools in the Western Cape, with the aim of coming up with the effective intervention strategy to curb stigma, discrimination, and prejudice. The researchers believe that the findings of this research will contribute new knowledge development in this field. For example, the benefits of this study to primary schools will be the retention of experienced, qualified, and skilled teachers and, in turn, this will result in increased productivity in the schools thus attaining quality education. Secondly, further research could be to look at high schools' principals' experiences in supporting teachers living with HIV/AIDS at high schools.

\section{Literature on Principals' experiences in supporting teachers living with HIV/AIDS}

According to Buchel (2006), "the principals serve as directors of their schools and as a result they should exhibit leadership role and responsibility". A director has a responsibility of dealing with various challenges in their school guided by the democratic governance structures of schools based on the South African Schools Act (SASA) of 1996. The major challenge they encounter in the era of HIV/AIDS is how "to protect teachers from the disease because HIV/AIDS affect everyone indiscriminately." Buchel (2006) further states that "principals need to have extensive experience of the effects of the pandemic as to deal with it as directors of transformation of principals and teachers is significance if schools and communities are to fight against the negative experiences of HIV/AIDS, stigma, and discrimination of teachers living with HIV/AIDS at schools". The systemic transformation of the principals' and teachers', as well as unlocking the principals' experiences in supporting teachers living with HIV/AIDS is located at the heart of this research.

Principals also face a challenge of making teachers to disclose their status. The actual aim of finding out their status is not to intimidate them, but it is to be able to support them so that they can remain versatile within the school for an extended period. HIV/AIDS is a disease that is manageable, and it would be the responsibility of the principals to advise such teachers as to what to do in managing the diseases.

Teachers living with HIV/AIDS are afraid of being stigmatised. The principal need to use his or her experiences to deal with this challenge and should thus deal with HIV/AIDS in a confidential manner and must treat as such to gain the confidence of those who have not yet disclosed their status or those who want to disclose. HIV/AIDS make some teachers vulnerable and as a result their performance plunges. There are principals who are inexperienced who may use their attitude to deal with teachers who are HIV/AID positive. They would advise them to go to areas or schools where they are not known. The advice will be a way of pushing these teachers away from the school because 
they as principals do not want to deal or interact with such teachers. The other challenge that would tap on the principals' experience is how to deal with the rate of absenteeism. The principals' experiences need to be driven by knowledge about the HIV/AIDS pandemic, encourage trust, caring and supporting teachers living with HIV/AIDS.

The principal needs to be a change agent in a school. He or she must come up with strategies to deal with HIV/AIDS in his/her school. He or she must deal with the challenges that emerge because of the pandemic at the school. The principal needs to adopt best practises implemented by schools in the neighbourhood. HEAIDS (2010), contends that "principals should be preventative agents". This implies that the principal as a social change agent need to know how to provide support and counselling to teachers living with HIV/AIDS. The principal should prevent teachers from being stigmatised and discriminated against. Primary schools normally lack principals who have the skills of how to deal with HIV/AIDS in the school environment. The principal should exercise collegial sensitivity in assisting teachers living with HIV/AIDS.

The principal should have experience of how to assist teachers living with HIV/AIDS once they are identified. The principal should further be reflective personally of their own attitudes, believes and behaviour in relation to HIV/AIDS. "Principals cannot be role models while they themselves are engaging in casual sex without consideration of HIV infection, HEAIDS (2010). Principals as leaders need to live in a responsible way which means they should be aware of their roles and responsibilities as leaders. It is essential for them to know their status before they advise teachers to go and test. This means that principals need to encourage teachers to read more about the disease and know much about this disease. It is always said that knowledge is power. Principals need to encourage teachers to alter their moral standards. Teachers need to be community ambassadors to curb the disease. They should encourage discussions around topics on HIV/AIDS. It is also essential for the department to organise workshops to allow the principals to scaffold the teachers. Principals need to study and understand the HIV/AIDS policy and be able to interpret it correctly and with understanding. Finally, principals need to reduce stigma, discrimination and disrespect of people who are living with HIV/AIDS.

\section{Research Method}

In this article, phenomenological design was used to explore and understand the primary school principals' experiences in supporting primary school teachers assumed to be living with HIV/AIDS in Gauteng East schools. The phenomenological design, according to Lichtman (2013:325), is a design within qualitative research, which has philosophical roots that emphasise the study of lived experiences. A phenomenological study aims at understanding perceptions, views, and/or a phenomenon that people have experienced (Leedy \& Ormrod, 2005:139). According to Lichtman (2013:124), the phenomenological design, also known as the science of pure phenomena, has a philosophical origin that gives prominence to the understanding of lived experiences.

Interviews were thus used as an instrument, in the collection of data. This instrument is seen been relevant, as it allows the researchers to gain more in-depth information from participants. That is why it is used in this study, to assist the researchers to understand the primary school principals' experiences in supporting teachers living with HIV/AIDS in Gauteng Province.

Below are some of the responses from the principals as participants during their interview sessions:

\begin{tabular}{|l|l|}
\hline $\begin{array}{l}\text { Researcher as } \\
\text { an interviewer }\end{array}$ & How does the principal cope with the challenges of HIV/AIDS? \\
\hline $\begin{array}{l}\text { Participant } \\
\text { response }\end{array}$ & $\begin{array}{l}\text { Coping with the challenges teachers' experiences is a real challenge for me as a principal. I have a } \\
\text { problem with teachers who arrive late at school. The challenge is that the teacher who is regularly late } \\
\text { is always regularly absent from school. They even afraid to report their leave of absence. They always } \\
\text { bring a doctor's letter as a reason why they are absent. As a principal it becomes a problem for me } \\
\text { when I discover in the morning that a teacher is missing. We do not have substitute teachers who we }\end{array}$ \\
\hline
\end{tabular}


can use as an emergency to look after the children of the teacher who has not showed up for school. Previously I have used school clerks as a reliever. I have used the groundsmen, the cleaners to assist to look after the children. I feel guilty because these people who have been used to relieve the absent teachers are not qualified to do so. I am aware that it is easy to use these people because my school is a primary school, and I could escape with this arrangement. What was going to happen if it was a high school? I do not say the primary school are not important, but it means is how I cope when I find myself in this crisis. There were times that I was afraid even to report to my IDSO regarding the situation. Teachers also influence children to be absent from school. The children also feel that what is the use to go to school because they also know that their teacher is regularly absent from school. Then I should also deal with the absence of children from school.

Participants were eager to receive training from the department and other NGO sources.

Participant responded by saying:

We appeal that we should be trained to protect our teachers from HIV/AIDS. I mean a manner of approach because HIV/AIDS is a sensitive issue that needs one to be sensitive and not offend people.

\section{Findings and Discussions of the Results}

The findings indicated that the epidemic's opportunistic diseases affected the teachers (such as recurring fevers, night sweats, weight loss, intense and mysterious tiredness, inflamed lymph glands in the groin or collar, and stomach diarrhoea that continues for more than seven days or longer). They can also include gastroenteritis, blemishes on the tongue, purplish blotches on or under the membrane, pneumonia, recollection loss, poor awareness and inventiveness, downheartedness, other nerve disarrays, tuberculosis, meningitis, and various forms of cancers, which affect both the physical and psychological well-being of teachers suffering from HIV/AIDS.

This research also revealed that teachers infected with HIV/AIDS normally withdraw from family, neighbours, friends, and colleagues after their status was confirmed and that they find it difficult to concentrate on their schoolwork as they become preoccupied with sickness and death. The findings in this study and in the literature correlate with previous research studies that it takes time for these teachers to come to terms with an HIV/AIDS-positive status. It has been revealed that teachers assumed to be living with HIV/AIDS suffer anxiety and depression and fear of discrimination and rejection (UNAIDS, 2006a). Some teachers are not supported because they had not declared their status; this endorses the findings of the interviews in this study, as they have not declared their status openly. Efforts are needed to find ways of providing these teachers with access to social support, care, and other forms of hospitality (UNAIDS, 2006a).

Chilisa (2012) notes that Manegold and Pather (2004) and Cook, Fritz and Mwoya (2003) have come up with two contradicting views pertaining to teachers assumed to be living with HIV/AIDS. Manegold and Pather (2004) maintain that a school is characterised by tension, conflict, and contradictions, which increase the vulnerability of teachers assumed to be living with HIV/AIDS. Cook et al. (2003) view the school and the principal as being supportive. The researcher in this study observed that treatment of teachers is not the same at different schools. Members of the SMT gave healthy and active teachers more attention and preference than those who looked fragile and vulnerable.

The complexity of HIV/AIDS requires efficient and effective managerial capacity and leadership through adversity of areas in order to react to the medicinal, civil, and social consequences of the epidemic (UNESCO-IIEP, 2009). The primary school principals' experiences are vital in dealing with a variety of challenges brought by HIV/AIDS in a school. The principal must manage various support structures, the community, teachers, parents, children, health care, employees, and counsellors at the school. Principals are the cornerstone of leadership in a school. They perform various essential roles and duties in a school that can include leaders, social workers, lawyers, psychologists, and advisors. Principals mentioned that they have challenges in trying to manage the school in the face of effects of HIV/AIDS. Having primary school teachers assumed to be living with HIV/AIDS, it means taking on the extra responsibility of calming tensions and providing support and this makes the management of the school to be negatively affected by increased teacher absenteeism. 


\section{Conclusion}

The study highlighted the exploration and description of the primary school principals' experiences in supporting teachers living with HIV/AIDS in Gauteng Province, South Africa. It was found through literature review that inadequate research on the topic of primary school principals' experiences in supporting teachers living with HIV/AIDS specifically in Gauteng Province was not widely and thoroughly conducted. The researchers are therefore believing that to be successful in combating and reducing the increase in HIV/AIDS amongst these teachers, more intense studies need to be conducted at micro and macro levels by all the organizations in South Africa.

\section{Acknowledgements}

I would like to acknowledge Gauteng Education District in South Africa for playing a major role in this study through allowing the researcher to embark on this sensitive topic of exploring and describing the primary school principals' experiences in supporting teachers living with HIV/AIDS in Gauteng Province, South Africa.

\section{References}

Bennel, P. (2005). The impact of the Aids Epidemic on Teachers in Sub-Saharan Africa. The Journal of Development Studies, 41(3).

Bronfenbrenner, U. (1986). Ecology of the family as a context for human development: Research perspectives. Developmental Psychology, 22(6), 723-742. https://doi.org/10.1037/oo12-1649.22.6.723

Buchel, A.J. (2006). The leadership role of the principal in dealing with the impact of HIV/AIDS in South African schools. Unpublished thesis. University of South Africa. Accessed on 12 April 2012. http://etd.unisa.ac.za/ETD-db/ETDdesc/describe?urn=etd-o8022006- 124509/unrestricted/o7chapter7.pdf.

Cook A.S., Fritz, J.J., \& Mwonya, R. (2003). Understanding the psychological and emotional needs of AIDS orphans in Africa. In A. Singhal \& W.S. Howard (Eds.). The children of Africa confront AIDS: From vulnerability to possibility. Athens: Ohio University Press.

DoE (Department of Education). (1999). National Education Policy on HIV/AIDS for Learners and Educators in Public Schools, and Students and Educators in Further Education and Training Institutions of The Department of Education. Government Gazette no 20327, 10 August 1999. Pretoria, South Africa.

HEAIDS, (2010). HIV and AIDS in Teacher Education-Evaluation Report of a Pilot Project in South African Higher Education Institutions. Pretoria: Higher Education South Africa.

Human science research council (hsrc), (2005). The health of our teachers a focus on hiv/aids in South African public schools, 2004/5 Survey, Report prepared for the education labour relation council. Human Science Research Council and Medical Council of South Africa: Pretoria.

Kelly, G. (2000). A manual for the Repertory grid, administration.

Lichtman, M. (2013). Qualitative Research in Education. $3^{\mathrm{RD}}$ Edition. Publisher: SAGE. ISBN: 978-1-4129-9532-o.

Louw, J., Shisana, O., Peltzer, k., \& Zungu, N. (2009). Examining the impact of HIV \& AIDS on South African Educators. South African Journal of education. Vol. 28: 205-217. EASA.

Mbelle, N. and Setswe, G. (2008). HIV and AIDS Strategy 2008-2012. (In Limpopo Department of Education, (2008). HIV and AIDS Strategy 2008-2012. November 2008). HSRC and IRISH AID Department of Foreign Affairs.

Sedibeng District Municipality. (2011) 2010-2011 Annual Report, 2011).

Shisana, O. (2013). Plenary Session 3, 20 June 2013. HIV/AIDS in South Africa: At last, the glass is half full. Speech presented by Dr Shisana at the $6^{\text {th }}$ South African Aids Conference in Durban.Human Science Research Council (HSRC).

Shisana, O. Peltzer, K. Zungu-Dirwayi, N. \& Louw, J. (2005). Integrated report on factors determining 'educator supply and demand in South African public schools. HSRC.

UNESCO. (2010) Background paper prepared for the education for all global monitoring report 2010. Reaching the marginalised literature review on HIV and aids education and marginalisation UNAIDS IATT on education 2009. UNESCO.

Wood, L., \& Webb, P. (2008). The perceptions and responses of South African principals regarding HIV and AIDS in their schools. Vulnerable children and youth studies, August 2008, 3(2): 143-149. Routledge Taylor and Francis Group. 